\title{
Machine Shop Shared Resource
}

National Cancer Institute

\section{Source}

National Cancer Institute. Machine Shop Shared Resource. NCI Thesaurus. Code C39446.

The Machine Shop Shared is available at Cancer Center to provide machining services,

sheet metal work, wood work, welding, and consulting in support of the research activities. 